\title{
MR Abstracts
}

Acting Editor-in-Chief: Robert P. Frankenthal - Associate Editors: Shigeyuki Somiya, Heinrich J. Wollenberger

Abstracts for December 1998 Journal of Materials Research

Volume 13, Number 12

\section{TABLE OF CONTENTS}

\section{COMMUNICATIONS}

A new hybrid two-zone/crucible furnace process for the growth of epitaxial $\mathrm{Tl}_{2} \mathrm{Ba}_{2} \mathrm{CaCu}_{2} \mathrm{O}_{8}$ superconducting films

M.P. Siegal, D.L. Overmyer, E.L. Venturini, F. Dominguez, R.R. Padilla

Micro instruments for submicron material studies

M.T.A. Saif, N.C. MacDonald

Novel calcium phosphate ceramics prepared by powder-sintering and crystallization of glasses in the pyrophosphate region

T. Kasuga, Y. Abe

Synthesis and $\mathrm{Na}^{+}$conduction properties of the ceramics of $\mathrm{Na}_{5} \mathrm{YSi}_{4} \mathrm{O}_{12}$-type phosphate-substituted solid solutions

K. Yamashita, M. Matsuda, T. Umegak

A novel organo-thermal reduction process for producing nanocrystalline $\mathrm{Ni}_{2} \mathrm{P}$ with a circular-shaped flake morphology

S-H. Yu, J. Yang, Y-S. Wu, Z-H. Han, L. Shu, Y. Xie, Y-T. Qian

Effects of electron beam irradiation on time to clear vision of misted dental mirror glass

K. Oguri, K. Fujita, M. Takahashi, Y. Omori, A. Tonegawa, N. Honda,

M. Ochi, K. Takayama, Y. Nishi

\section{ARTICLES}

Metallothermic reduction as an electronically mediated reaction

T.H. Okabe, D.R. Sadoway

The mechanism of sputter-induced epitaxy modification in $\mathrm{YBa}_{2} \mathrm{Cu}_{3} \mathrm{O}_{7-x}$ (001) films grown on $\mathbf{M g O}$ (001) substrates

Y. Huang, B.V. Vuchic, M. Carmody, P.M. Baldo, K.L. Merkle, D.B. Buchholz, S. Mahajan, J.S. Lei, P.R. Markworth, R.P.H. Chang

Microstructural studies of $\mathrm{PrBa}_{2} \mathrm{Cu}_{3} \mathrm{O}_{y}$ during melt processing E.S. Reddy, T. Rajasekharan

Preparation of crystalline CdSe particles by chemical bath deposition 0. Yamamoto, T. Sasamoto, M. Inagaki

High-temperature stability of a nanocrystalline structure in a TIAI alloy prepared by mechanical alloying and hot isostatic pressing

O.N. Senkov, N. Srisukhumbowornchai, M.L. Öveçoglu, F.H. Froes

Surface analysis of a heat treated Al-containing iron-based superalloy M.F. López, A. Gutiérrez, M.C. García-Alonso, M.L. Escudero

Accelerated sintering and phase transformation of $\mathrm{TiO}_{2}$ in microwave radiation

Z-P. Xie, X-D. Fan, Y. Huang
The fabrication of near net-shaped spinel bodies by the oxidative transformation of $\mathrm{Mg} / \mathrm{Al}_{2} \mathrm{O}_{3}$ precursors

P. Kumar, K.H. Sandhage

Structural and electrical properties of excess $\mathrm{PhO}$ doped $\mathrm{Pb}\left(\mathrm{Zr}_{0.52} \mathrm{Ti}_{0.48}\right) \mathrm{O}_{3}$ thin films using if magnetron sputtering method T.S. Kim, D.J. Kim, J.K. Lee, H.J. Jung

The effect of oxygen partial pressure during cooling on lead zirconate titanate thin film growth by using if magnetron sputtering method D.J. Kim, T.S. Kim, J.K. Lee, H.J. Jung

Grain boundary structure in $\mathrm{TiO}_{2}$-excess barium titanate T. Yamamoto, Y. Ikuhara, K. Hayashi, T. Sakuma

Internal friction and torsional creep behavior of chemically vapor deposited boron nitride

G. Pezzotti, H-J. Kleebe, K. Ota, T. Nishida

Synthesis of carbon nitride crystals at high pressures and temperatures D.W. He, F.X. Zhang, X.Y. Zhang, Z.C. Qin, M. Zhang, R.P. Liu, Y.F. Xu, W.K. Wang

Absorption length for photon propagation in highly dense colloidal dispersions

R. Garg, R.K. Prud'homme, I.A. Aksay, F. Liu, R.R. Alfano

Weight loss and gas evolution during sintering of silicon nitride powders synthesized by silica reduction and imide decomposition

Y. Goto, Y. Ohnuma

Effect of sintering additive composition on the thermal conductivity of silicon nitride

Y. Okamoto, N. Hirosaki, M. Ando, F. Munakata, Y. Akimune

Short-range dislocation interactions using molecular dynamics: Annihilation of screw dislocations

S. Swaminarayan, R. LeSar, P. Lomdahl, D. Beazley

The crystallization and growth of $\mathrm{AlB}_{2}$ single crystal flakes in aluminum C. Deppisch, G. Liu, A. Hall, Y. Xu, A. Zangvil, J.K. Shang, J. Economy

Mechanochemical reactions in the system $\mathrm{FeTiO}_{3}-\mathrm{Si}$

Y. Chen, J.S. Williams

Predicting the spreading kinetics of high-temperature liquids on solid surfaces

D.A. Weirauch, Jr.

Crystal structure and dielectric property of epitaxially grown $(\mathrm{Ba}, \mathrm{Sr}) \mathrm{TiO}_{3}$ thin film prepared by metalorganic chemical vapor deposition H. Funakubo, Y. Takeshima, D. Nagano, K. Shinozaki, N. Mizutani 
Prediction of nanoindentation hardness profile from a loaddisplacement curve

K.W. Xu, G.L. Hou, B.C. Hendrix, J.W. He, Y. Sun, S. Zheng,

A. Bloyce, T. Bell

Theory of the charged cluster formation in the low pressure synthesis of diamond: Part I. Charge-induced nucleation

H.M. Jang, N.M. Hwang

Theory of the charged cluster formation in the low pressure synthesis of diamond: Part II. Free energy function and thermodynamic stability H.M. Jang, N.M. Hwang

Preparation and photoconductivity of poly[4-vinyl-pyridine]-CoPc self-assembled film

M-M. Shi, M. Wang, H-Z. Chen
The adhesion energy between polymer thin films and self-assembled monolayers

A.V. Zhuk, A.G. Evans, J.W. Hutchinson, G.M. Whitesides

Quantitative nanoscale mechanical properties of a phase segregated homopolymer surface

J.F. Graham, M. Kovar, P.R. Norton, P. Pappalardo, J. Van Loon,

O.L. Warren

A transmission electron microscopy investigation of SiC films grown on Si(111) substrates by solid-source molecular beam epitaxy

U. Kaiser, S.B. Newcomb, W.M. Stobbs, M. Adamik, A. Fissel, W. Richter

Controlled partial melting during processing of dipcoated

Bi-2212/Ag tapes.

A.L. Crossley, J.L. MacManus-Driscoll

\section{ABSTRACTS}

\section{COMMUNICATIONS}

A new hybrid two-zone/crucible furnace process for the growth of epilaxial $\mathrm{Tl}_{2} \mathrm{Ba}_{2} \mathrm{CaCl}_{2} \mathrm{O}_{8}$ superconducting films

M.P. Siegal, D.L. Overmyer, E.L. Venturini, F. Dominguez, R.R. Padilla (Sandia National Laboratories)

Epitaxial $\mathrm{Tl}_{2} \mathrm{Ba}_{2} \mathrm{CaCu}_{2} \mathrm{O}_{8}$ (T1-2212) films $\sim 5500 \AA$ thick are grown on $\mathrm{LaAlO}_{3}(100)$ substrates using a new hybrid two-zone/crucible furnace process enabling precise control of thallination. This method combines the best features of both conventional crucible and two-zone processing for the first time: superb film properties and reduced handling of hazardous TI-oxide powders. Single-phase, highly c-axis oriented TI-2212 films are grown with smooth morphology, Meissner transition $\sim 103 \mathrm{~K}$, and critical current density $\sim 1.1 \times 10^{7} \mathrm{~A} / \mathrm{cm}^{2}$ at $5 \mathrm{~K}$ for twenty consecutive runs without having to change or add to the TI-oxide source.

Order No.: JA812-001

(C) 1998 MRS

Micro instruments for submicron material studies

M.T.A. Saif, N.C. MacDonald

(Cornell University)

We present two micro instruments for submicron scale material characterization. One of the instruments applies torsion on two single crystal silicon bars with square cross sections, $1 \mu \mathrm{m}^{2}$ and $2.25 \mu \mathrm{m}^{2}$, until fracture. The maximum shear stress prior to fracture is found to be 5.6 and $2.6 \mathrm{GPa}$, respectively. The second instrument applies tension on a composite (aluminum-silicon dioxide) beam, $1 \times 1.5 \mu \mathrm{m}^{2}$ in cross section. The beam fails at $220 \mu \mathrm{N}$. In both the experiments, the samples are designed, patterned, and cofabricated with the instruments. The micro instruments' small size, low thermal mass, vacuum compatibility, and built-in vibration isolation allow material characterization to be performed over a wide range of environmental conditions: high vacuum (electron microscopy and surface analysis), high humidity, high pressure, and high and low temperatures.

Order No.: JA812-002

(C) 1998 MRS

Novel calcium phosphate ceramics prepared by powder-sintering and crystallization of glasses in the pyrophosphate region

T. Kasuga, Y. Abe

(Nagoya Institute of Technology)

Silica-free phosphate glasses containing small amounts of $\mathrm{Na}_{2} \mathrm{O}$ and $\mathrm{TiO}_{2}$ with the composition of $\mathrm{Ca} / \mathrm{P}=1$ in atomic ratio were obtained. When powder-compacts of the glasses were heated at $850^{\circ} \mathrm{C}$, they crystallized and subsequently sintered, resulting in glass-ceramics containing $\beta-\mathrm{Ca}_{3}\left(\mathrm{PO}_{4}\right)_{2}$ and $\beta-\mathrm{Ca}_{2} \mathrm{P}_{2} \mathrm{O}_{7}$ crystalline phases. The glass-ceramics show relatively high fracture toughness of $\mathrm{K}_{\mathrm{IC}} \approx 2 \mathrm{MPa} \cdot \mathrm{m}^{0.5}$. By soaking in sim- ulated body fluid at $37^{\circ} \mathrm{C}$, a calcium phosphate phase was formed newly on the surface of the glass-ceramics.

Order No.: JA812-003

(C) $1998 \mathrm{MRS}$

Synthesis and $\mathrm{Na}^{+}$conduction properties of the ceramics of $\mathrm{Na}_{5} \mathrm{YSi}_{4} \mathrm{O}_{12}$-type phosphate-substituted solid solutions K. Yamashita ${ }^{\star}$, M. Matsuda+, T. Umegaki\#t

$\left({ }^{*}\right.$ Tokyo Medical and Dental University, ${ }^{+}$Okayama University,

\#Tokyo Metropolitan University)

The $\mathrm{Na}^{+}$-superionic conducting ceramics with $\mathrm{Na}_{5} \mathrm{YSi}_{4} \mathrm{O}_{12}$-type structure were synthesized using the composition formula of $\mathrm{Na}_{3+3 x-y} \mathrm{Y}_{1-x^{-}}$ $\mathrm{P}_{y} \mathrm{Si}_{3-y} \mathrm{O}_{9}$, in which some portions of $\mathrm{Na}^{+}$ions are considered to replace

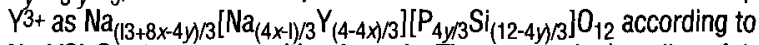
$\mathrm{Na}_{5} \mathrm{YSi}_{4} \mathrm{O}_{12}$-type composition formula. The average ionic radius of the 6-coordinated $\mathrm{Y}^{3+}$ sites $\left(=(4 x-1) / 3 \times \mathrm{r}_{\mathrm{Na}}+(4-4 x) / 3 \times \mathrm{r}_{\mathrm{Y}}\right)$ approximately covered the range of $r_{\mathrm{Gd}}(\mathrm{nm})$ and to $\mathrm{r}_{\mathrm{Sm}}(\mathrm{nm})$. The ionic conduction properties were strongly dependent upon the combination of composition parameters, $x$ and $y$. In this report, the dependence of conduction properties on the composition is discussed on the basis of structural considerations.

Order No.: JA812-004

(C) 1998 MRS

A novel organo-thermal reduction process for producing nanocrystalline $\mathrm{Ni}_{2} \mathrm{P}$ with a circular-shaped flake morphology

S-H. Yu, J. Yang, Y-S. Wu, Z-H. Han, L. Shu, Y. Xie, Y-T. Oian

(University of Science and Technology of China)

An organo-thermal reduction process has been successfully developed for synthesis of nanocrystalline $\mathrm{Ni}_{2} \mathrm{P}$ in benzene at $140^{\circ} \mathrm{C}$. $\mathrm{X}$-ray powder diffraction pattern (XRD) indicated that the product was pure hexagonal $\mathrm{Ni}_{2} \mathrm{P}$ phase with cell constants $\mathrm{a}=0.5866, \mathrm{C}=0.3377 \mathrm{~nm}$. Transmission electron microscopy (TEM) showed that the average particle size of the powders was $40 \mathrm{~nm}$ with a circular-shaped flake morphology. Order No.: JA812-005

(C) 1998 MRS

Effects of electron beam irradiation on time to clear vision of misted dental mirror glass

K. Oguri*, K. Fujita*, M. Takahashi*, Y. Omori*, A. Tonegawa*, N. Honda*, M. Ochi ${ }^{+}$, K. Takayama ${ }^{\star}$, Y Nishi $^{*}$

('Tokai University, ${ }^{+}$I wasaki Electric Group Company)

A misting free dental mirror is obtained near the human temperature under the saturated humidity atmosphere by use of the sheet electron beam irradiation treatment. It is shown that electron beam irradiation treatment decreases the time to clear vision in a misted mirror. This effect is due to an enhancement of the interfacial energy between the dental mirror glass and water.

Order No.: JA812-006

(C) 1998 MRS 


\section{ARTICLES}

Metallothermic reduction as an electronically mediated reaction

T.H. Okabe, D.R. Sadoway

(Massachusetts institute of Technology)

The commonly held view that metallothermic reduction is strictly a chemical reaction and that the process is rate limited by mass transfer has been found to be incomplete. In a study of the production of tantalum powder by the reaction of $\mathrm{K}_{2} \mathrm{TaF}_{7}$ with sodium, it has been shown that there are two dominant kinetic pathways, both involving electron transfer. Further-more, the overall rate of reaction is limited by electron transport between the reactants. This indicates that metallothermic reduction is an "electronically mediated reaction" (EMR). Experiments found that the location of the tantalum deposit and its morphology are governed by the reaction pathway.

Order No.: JA812-007

(C) 1998 MRS

The mechanism of sputter-induced epitaxy modification in $\mathrm{YBa}_{2} \mathrm{Cu}_{3} \mathrm{O}_{7-x}$ (001) films grown on $\mathrm{MgO}$ (001) substrates

Y. Huang ${ }^{*}$, B.V. Vuchic*, M. Carmody*, P.M. Baldo*, K.L. Merkle*,

D.B. Buchholz ${ }^{+}$, S. Mahajan ${ }^{+}$, J.S. Lei ${ }^{+}$, P.R. Markworth ${ }^{+}$, R.P.H. Chang ${ }^{+}$

("Argonne National Laboratory, ${ }^{+}$Northwestern University)

The sputter-induced epitaxy change of in-plane orientation occurring in $\mathrm{YBa}_{2} \mathrm{Cu}_{3} \mathrm{O}_{7-x}(001)$ thin films grown on $\mathrm{MgO}(001)$ substrates by pulsed organo-metallic beam epitaxy (POMBE) is investigated by a series of film growth and characterization experiments, including RBS and TEM. The factors influencing the orientation change are systematically studied. The experimental results suggest that the substrate surface morphology change caused by the ion sputtering and the Ar ion implantation in the substrate surface layer are not the major factors that affect the orientation change. Instead, the implantation of $W$ ions, which come from the hot filament of the ion gun, and the initial Ba deposition layer in the YBCO film growth play the most important roles in controlling the epitaxy orientation change. Microstructure studies show that a $\mathrm{Ba}_{x} \mathrm{Mg}_{1-x} \mathrm{O}$ buffer layer is formed on top of the sputtered substrate surface due to $\mathrm{Ba}$ diffusion into the $W$ implanted layer. It is believed that the formation of this buffer layer relieves the large lattice mismatch and changes the YBCO film from the $45^{\circ}$ oriented growth to the $0^{\circ}$ oriented growth.

Order No.: JA812-008

(C) 1998 MRS

\section{Microstructural studies of $\mathrm{PrBa}_{2} \mathrm{Cu}_{3} \mathrm{O}_{y}$ during melt processing}

E.S. Reddy, T. Rajasekharan

(Defence Metallurgical Research Laboratory)

The microstructures of $\mathrm{PrBa}_{2} \mathrm{Cu}_{3} \mathrm{O}_{y}$ during melt processing have been studied for the samples quenched at different stages of the thermal cycle. The absence of $\mathrm{Pr}_{2} \mathrm{BaCuO}_{5}$ phase in the $\mathrm{Pr}-\mathrm{Ba}-\mathrm{Cu}-\mathrm{O}$ phase diagram, in analogues to $\mathrm{Y}_{2} \mathrm{BaCuO}_{5}$ (211) phase in the $\mathrm{Y}-\mathrm{Ba}-\mathrm{Cu}-\mathrm{O}$ system, makes it interesting to study the microstructure of $\mathrm{PrBa}_{2} \mathrm{Cu}_{3} \mathrm{O}_{y}(\mathrm{Pr}-123)$ during melt processing. The nature and morphology of the pro-peritectic particles, the nucleation of $\mathrm{Pr}-123$, and the microstructures resulting from melt processing are investigated and discussed as compared with those in $\mathrm{YBa}_{2} \mathrm{Cu}_{3} \mathrm{O}_{y}$. At the pro-peritectic stage the morphology of $\mathrm{PrBaO}_{3}(\mathrm{Pr}-110)$ particles is angular. $\mathrm{Pr}-123$ is found to nucleate on all $\mathrm{Pr}-110$ particles with a needle like morphology whereas in other 123 systerns, no preferred.morphology for the 123 during nucleation is observed. The melt textured microstructure of $\mathrm{Pr}-123$ revealed similar features like domain formation with trapped properitectic phase. But the only difference is the absence of platelet gaps within domains as observed in other 123 systems. All these observations suggest that, as compared to other 123 systems, the microstructure of Pr-Ba-Cu- 0 system behaves differently due to the absence of analogous 211 phase.

Order No.: JA812-009

(c) 1998 MRS
Preparation of crystalline CdSe particles by chemical bath deposition 0. Yamamoto*, T. Sasamoto*, M. Inagaki ${ }^{+}$ ("Kanagawa Institute of Technology, ${ }^{\star}$ Hokkaido University)

Crystalline CdSe particles were prepared by keeping the precursor solutions at temperatures above $60^{\circ} \mathrm{C}$. It was essential to use sodium sulfite as the stabilizing agent for selenium ions and sodium dicarboxylate as the complexing agent for cadmium in the precursor solution. The principal crystalline phase of the samples obtained at $60^{\circ} \mathrm{C}$ was the cubic zincblende-type phase, but those prepared at $80^{\circ} \mathrm{C}$ coexisted with the hexagonal wurtite-type phase. The ratio of cadmium to selenium in the samples decreased with an increase of the concentration of selenourea in the precursor solutions, irrespective of the kind of complex agents and the keeping time of the precursor solutions. The band-gap energy of CdSe with an atomic ratio $(\mathrm{Cd} / \mathrm{Se})$ of 1 showed a value of $1.74 \mathrm{eV}$, but that with the ratio of 2.3 gave a slightly smaller value of $1.42 \mathrm{eV}$.

Order No.: JA812-010

(C) 1998 MRS

High-lemperature stability of a nanocrystalline structure in a TiAl alloy prepared by mechanical alloying and hot isostatic pressing O.N. Senkov*, N. Srisukhumbowornchai ${ }^{*}$, M.L. Öveçoglu ${ }^{+}$, F.H. Froes ${ }^{*}$ ("University of Idaho, +/stanbul Technical University)

A fully dense nanocrystalline compact of the Ti-47AI-3Cr (at. \%) alloy was produced by mechanical alloying and hot isostatic pressing at $725^{\circ} \mathrm{C}$. Microstructure characteristics and grain growth behavior of this compact were studied after annealing for up to 800 hours in the temperature range of 725 to $1200^{\circ} \mathrm{C}$, using analytical transmission electron microscopy techniques. The temperature and time dependencies of the grain sizes and the grain size distributions were determined. The grain growth occurred with a time- and temperature-invariant single-peak grain size distribution (when normalized by the mean grain size), which was consistent with normal grain growth. The experimentally measured grain growth exponent decreased from 10 to 4.6 when the temperature was increased. The grain growth kinetics were described by a single thermally activated rate process limited by a permanent pinning force on the grain boundaries. The microhardness decreased on annealing and followed the Hall-Petch relationship with the parameters $\mathrm{H}_{v 0}=5.8 \mathrm{GPa}$ and $\mathrm{K}_{\mathrm{H}}=$ $0.16 \mathrm{MPa} \cdot \mathrm{m}^{0.5}$.

Order No.: JA812-011

(C) 1998 MRS

Surface analysis of a heat treated Al-containing iron-based superalloy M.F. López, A. Gutiérrez, M.C. García-Alonso, M.L. Escudero

(Centro Nacional de Investigaciones Metalúrgicas)

The surface composition of MA956 superalloy both as-received and after four exposure times at $1100^{\circ} \mathrm{C}$ has been investigated by EDX arid XPS. The passive layer of the as-received sample is mainly formed by $\mathrm{Cr}$ and $\mathrm{Fe}$-oxides. Heat treatment leads to the formation of an alumina layer on which small nodules grow. XPS spectra evidence the presence of titanium and yttrium oxides at the surface of the heat treated samples suggesting $Y$ and Ti outward diffusion through the alumina layer. Iron and chromium oxides at the topmost surface layers are observed only for short heat treatment times.

Order No.: JA812-012

(C) 1998 MRS

Accelerated sintering and phase transiormation of $\mathrm{TiO}_{2}$ in microwave radiation

Z-P. Xie, X-D. Fan, Y. Huang

(Tsinghua University)

The sintering process and phase-transformation of submicrometer powder compacts of $\mathrm{TiO}_{2}$ were investigated using $2.45 \mathrm{GHz}$ microwave radiation. The microwave-sintered samples were densified more rapidly and at much shorter time and lower temperature than that of the conventionally sintered samples. Also, an accelerated phase transformation from 
anatase to rutile was observed in microwave processing where the dwell time is cut down from $6 \mathrm{~h}$ in conventional to $30 \mathrm{~min}$. in microwave at $1000^{\circ} \mathrm{C}$. The samples sintered in microwave show a refined microstructure and smaller grain sizes at high density near $98-99 \%$ theoretical. In addition, the reason of rapidly heating behavior and enhanced sintering on $\mathrm{TiO}_{2}$ in microwave was discussed.

Order No.: JA812-013

(C) 1998 MRS

The fabrication of near net-shaped spinel bodies by the oxidative transformation of $\mathrm{Mg} / \mathrm{Al}_{2} \mathrm{O}_{3}$ precursors

P. Kumar, K.H. Sandhage

(The Ohio State University)

The feasibility of transforming shaped $\mathrm{Mg}-\mathrm{Al}_{2} \mathrm{O}_{3}$-bearing precursors into monolithic spinel $\left(\mathrm{MgAl}_{2} \mathrm{O}_{4}\right)$ bodies with a retention of shape and dimensions has been demonstrated. Dense, shaped precursors (disks, bars) were fabricated by the pressureless infiltration of molten $\mathrm{Mg}$ into porous $\mathrm{Al}_{2} \mathrm{O}_{3}$ preforms. After solidification (and machining, in the case of bar-shaped specimens), the $\mathrm{Mg}$-bearing precursors were oxidized in flowing $\mathrm{O}_{2}(\mathrm{~g})$ at $430-700^{\circ} \mathrm{C}$. Post-oxidation annealing at $1200^{\circ} \mathrm{C}$ resulted in the conversion of $\mathrm{MgO}$ and $\mathrm{Al}_{2} \mathrm{O}_{3}$ into $\mathrm{MgAl}_{2} \mathrm{O}_{4}$. After sintering at $1700^{\circ} \mathrm{C}$, spinel bodies that retained the precursor dimensions (to within $0.65 \%$ ) were produced. Phase and microstructural analyses at various stages of processing are discussed.

Order No.: JAB12-014

(c) 1998 MRS

Structural and electrical properties of excess $\mathrm{PbO}$ doped $\mathrm{Pb}\left(\mathrm{Zr}_{0.52} \mathrm{Ti}_{0.48}\right) \mathrm{O}_{3}$ thin films using if magnetron sputtering method T.S. Kim, D.J. Kim, J.K. Lee, H.J. Jung

(KIST)

Well crystallized $\mathrm{Pb}\left(\mathrm{Zr}_{0.52} \mathrm{Ti}_{0.48}\right) \mathrm{O}_{3}$ thin films (4000 $\AA$ thickness) can be synthesized on $\mathrm{Pt} / \mathrm{Ti} / \mathrm{SiO}_{2} / \mathrm{Si}(100)$ substrate at the temperature as low as $520^{\circ} \mathrm{C}$. The polycrystalline PZT perovskite phase formation was confirmed with XRD analysis, and growth morphologies were studied with a SEM. The electrical properties of PZT thin films were characterized through P-E hysteresis curve, dielectric constant, and loss, fatigue, and leakage current measurements. Remanent polarization $\left(P_{r}\right)$ and coercive field $\left(E_{c}\right)$ of asgrown film were $8-30 \mu \mathrm{C} / \mathrm{cm}^{2}$ and $24-64 \mathrm{kV} / \mathrm{cm}$ with the variation of applied voltage (5-15 V). The post annealing enhances the electrical properties even at $500^{\circ} \mathrm{C}$, which is below the as-grown temperature $\left(520^{\circ} \mathrm{C}\right)$. The average polarization loss after applying rectangular pulse $(\mathrm{V} p-\mathrm{p}=10 \mathrm{~V})$ up to $10^{11}$ cycles was $40.9 \%$ for $300 \mu \mathrm{m}$ small dot and $22 \%$ for $500 \mu \mathrm{m}$ large dot, which are relatively improved values for platinum electrode. The values of dielectric constant $\left(\varepsilon^{\prime}\right)$ and tan $\delta$ measured with small signal sign wave $(1 \mathrm{~V}, 10 \mathrm{kHz})$ were 1207 and 0.066 in the case of as-grown film.

Order No.: JA812-015

(C) 1998 MRS

The effect of oxygen partial pressure during cooling on lead zirconate titanate thin film growth by using if magnetron sputtering method D.J. Kim, T.S. Kim, J.K. Lee, H.J. Jung

(KIST)

The lead zirconate titanate (PZT) thin film was deposited on platinized silicon wafer substrate by if magnetron sputtering method. In order to investigate an effect of cooling ambient, oxygen partial pressure was controlled during cooling PZT films. The PZT films cooled at lower oxygen partial pressure had perovskite phase and pyrochlore phase in both asgrown and post-annealed films, but, in the PZT films cooled at higher oxygen partial pressure, pyrochlore phases were not detected by XRD. As the oxygen partial pressure became lower during cooling, the capacitors had low values of remanent polarization and coercive field for as-grown films. The PZT capacitor with such a low value was recovered by post-annealing in air, but its electrical properties have the same tendency before and after annealing. Microstructure was also affected by cooling ambient. Higher oxygen partial pressure on cooling reduced the number of very fine grain and enhanced uniform grain distribution. Fatigue characteristics were also enhanced by cooling at higher oxygen partial pressure. However, the imprint was negligible irrespective of oxygen partial pressure upon cooling. The cooling procedure at higher oxygen ambients is believed to reduce the amounts of non-ferroelectric second phases and oxygen vacancies. We find that oxygen partial pressure during cooling is a considerable process parameter. Therefore, care should be taken in treating parameter after depositing films.

Order No.: JA812-016

(C) 1998 MRS

Grain boundary structure in $\mathrm{TiO}_{2}$-excess barium titanate

T. Yamamoto, Y. Ikuhara, K. Hayashi, T. Sakuma

(The University of Tokyo)

Grain boundary structure was examined in $0.1 \mathrm{~mol}^{\%} \mathrm{TiO}_{2}$ excess $\mathrm{BaTiO}_{3}$ by HRTEM and EELS. Their grain boundaries were mostly facetted with $\{210\}$ type habit. The facetted boundaries were characterized to be associated with an extra $\mathrm{Ti}-\mathrm{O}_{2}$ bond with the rutile-like structure. The grain growth behavior in a small $\mathrm{TiO}_{2}$-excess $\mathrm{BaTiO}_{3}$ is discussed from the viewpoint of grain boundary structure.

Order No.: JA812-017

(C) 1998 MRS

\section{Internal friction and torsional creep behavior of chemically vapor deposited boron nitride}

G. Pezzotti*, H-J. Kleebe ${ }^{+}$, K. Ota\#, T. Nishida*

("Kyoto Institute of Technology, + Universität Bayreuth, "Osaka University)

Dense hexagonal BN processed via chemical vapor deposition (CVD) was tested with respect to damping, shear modulus, and torsional creep rate up to temperatures as high as $\approx 2300^{\circ} \mathrm{C}$. The microstructural characteristics of the material both before and after creep testing were studied by high-resolution electron microscopy (HREM). The CVD deposition process yields a homogeneous nanosized microstructure with no other secondary phase detectable. Damping experiments revealed no plastic relaxation during testing up to $\approx 2000^{\circ} \mathrm{C}$, which is consistent to the fact that also no creep deformation could be detected below such a high temperature. Small porosity and an increased amorphization process were noted by HREM inspection after stress exposure at $\approx 2300^{\circ} \mathrm{C}$. These phenomena may be responsible for both the enhanced damping capacity and the creep rate of the material which, in the range of the present testing conditions, seems to follow the simple viscoelastic behavior of a Maxwell solid.

Order No.: JA812-018

(C) 1998 MRS

Synthesis of carbon nitride crystals at high pressures and temperatures D.W. He*, F.X. Zhang*, X.Y. Zhang*, Z.C. Qin*, M. Zhang*, R.P. Liu* Y.F. Xu, W.K. Wang ${ }^{*}$

('Chinese Academy of Science, + Yan Shan University)

Carbon nitride crystals have been sythesized from $\mathrm{C}_{3} \mathrm{~N}_{4} \mathrm{H}_{4}$ in the presence of a nickel-based alloy or cobalt as a catalyst at high pressure of $7 \mathrm{GPa}$ and temperature of about $1400^{\circ} \mathrm{C}$. Scanning electron microscopy showed rod-like well-faceted crystals with size of several micrometers, and the $\mathrm{N}$ content in these carbon nitride crystals was $47 \sim 62 \%$. $\mathrm{X}$-ray diffraction indicated the crystals were composed of $\alpha-C_{3} N_{4}$ and $\beta-C_{3} N_{4}$. The experimental lattice constants of $\alpha-C_{3} \mathrm{~N}_{4}(a=6.425 \AA, c=4.715 \AA)$ and $\beta$ $\mathrm{C}_{3} \mathrm{~N}_{4}(\mathrm{a}=6.419 \AA, \mathrm{C}=2.425 \AA)$ agree with ab-initio calculations very well. Order No.: JA812-019

(C) 1998 MRS

\section{Absorption length for photon propagation in highly dense colloidal dispersions}

R. Garg ${ }^{\star}$, R.K. Prud'homme*, I.A. Aksay*, F. Liu+, R.R. Alfano+

("Princeton University, +City University of New York)

The absorption length for photon propagation in highly concentrated colloidal dispersions calculated from temporal intensity profiles of 100 femto-second pulses is much longer than the absorption length obtained from the measurements of static light transmission in the pure continuous phase fluid. The difference between these two values is explained on the basis of small inter-particle spacing at high concentration of particles and hence shorter path traveled by photons through the absorbing medium relative to the total diffusive path in the dispersion. The two values are in 
good agreement when we re-scale the absorption length with the interparticle separation.

Order No.: JA812-020

(C) 1998 MRS

Weight loss and gas evolution during sintering of silicon nitride powders synthesized by silica reduction and imide decomposition

Y. Goto, Y. Ohnuma

(Toshiba Corporation)

The relationships between weight loss, gas evolution, and other changes during sintering were investigated for silicon nitride powders synthesized by silica reduction and imide decomposition. Small weight losses were detected for all powders at low temperatures (below $1400^{\circ} \mathrm{C}$ ) and large weight losses were found to occur for the silica-reduction powders at high temperatures $\left(1400-1800^{\circ} \mathrm{C}\right)$. Only CO was detected in the sampled gases during sintering, and $\mathrm{CO}$ evolution peaks were seen at around 900-1200 (broad), 1400 , and $1600^{\circ} \mathrm{C}$. The main deposited material around the samples was SiO. The weight losses at low temperatures were thought to be caused by evaporation of residual binder or adsorbed substances. The main causes of the large weight losses at high temperatures were thought to be $\mathrm{CO}$ and $\mathrm{SiO}$ evolutions, and $\mathrm{CO}$ evolution at around $1600^{\circ} \mathrm{C}$ probably originated from the liquid phase accompanied by $\alpha-\mathrm{Si}_{3} \mathrm{~N}_{4}$ to $\beta-\mathrm{Si}_{3} \mathrm{~N}_{4}$ transformation.

Order No.: JA812-021

(C) 1998 MRS

\section{Effect of sintering additive composition on the thermal conductivity of} silicon nitride

Y. Okamoto, N. Hirosaki, M. Ando, F. Munakata, Y. Akimune

(Nissan Motor Co., Ltd.)

The thermal conductivity of silicon nitride prepared with varying sintering additive compositions was studied. Samples of $\mathrm{Si}_{3} \mathrm{~N}_{4}+0.5 \mathrm{~mol} \%$ $\mathrm{Y}_{2} \mathrm{O}_{3}+0.5 \mathrm{~mol} \% \mathrm{Nd}_{2} \mathrm{O}_{3}$ and a further additional agent were gas pressure sintered at $2173 \mathrm{~K}$. MgO or $\mathrm{Al}_{2} \mathrm{O}_{3}$ was employed as the additional agent. While both agents improved sinterability, the former promoted grain growth, and the latter suppressed it. Thermal conductivity increased with increasing MgO content, and a maximum value of $128 \mathrm{Wm}^{-1} \mathrm{~K}^{-1}$ was attained when $2 \mathrm{~mol} \% \mathrm{MgO}$ was added. In contrast, addition of $\mathrm{Al}_{2} \mathrm{O}_{3}$ degrades thermal conductivity. This is probably due to the suppression of grain growth and the dissolution of $\mathrm{Al}_{2} \mathrm{O}_{3}$ into $\mathrm{Si}_{3} \mathrm{~N}_{4}$ grains

Order No.: JAB12-022

(C) 1998 MRS

Short-range dislocation interactions using molecular dynamics: Annihilation of screw dislocations

S. Swaminarayan, R. LeSar, P. Lomdahl, D. Beazley

(Los Alamos National Laboratory)

We present results of a large-scale atomistic study of the annihilation of oppositely-signed screw dislocations in an fcc metal using molecular dynamics (MD) and an Embedded-Atom-Method (EAM) potential for Cu. The mechanisms of the annihilation are studied in detail. From the simulation results, we determined the interaction energy between the disiocations as a function of separation. These results are compared with predictions from linear elasticity to examine the onset of non-linear-elastic interactions. The applicability of heuristic models for annihilation of dislocations in large-scale dislocation dynamics simulations is discussed in the light of these results.

Order No.: JA812-023

(C) 1998 MRS

The crystallization and growth of $\mathrm{AlB}_{2}$ single crystal flakes in aluminum C. Deppisch, G. Liu, A. Hall, Y. Xu, A. Zangvil, J.K. Shang, J. Economy (University of Illinois-Urbana)

An in-situ high temperature heat treatment was used to investigate the crystallization and growth behavior of $\mathrm{AlB}_{2}$ flakes in aluminum. Aluminum samples containing $1.8 \%$ boron were heated above the liquidus and then rapidly cooled through the $\mathrm{Al}_{(\mathrm{L})}+\mathrm{AlB}_{12}$ region to avoid the formation of $\mathrm{AlB}_{12}$ crystals. Subsequently, a homogeneous distribution of high aspect ratio $\mathrm{AlB}_{2}$ flakes crystallized upon holding below the peritectic transition temperature. Growth rate in the (a) and (c) dimensions increased during elevated hold temperatures below the peritectic transition temperature. Surprisingly, faster cooling rates from above the liquidus to room temperature resulted in thinner, wider flakes. Similar to graphite, this phenomenon is believed to result from a need to accommodate a changing misfit strain energy between the solidifying aluminum and the growing $\mathrm{AlB}_{2}$ flakes.

Order No.: JA812-024

(C) 1998 MRS

Mechanochemical reactions in the system $\mathrm{FeTiO}_{3}-\mathrm{Si}$

Y. Chen, J.S. Williams

(The Australian National University)

Mechanochemical reactions in the system $\mathrm{FeTiO}_{3}$-Si have been investigated as functions of the powder composition and milling conditions, using $x$-ray diffraction and thermal analyses. Reduction reactions of $\mathrm{FeTiO}_{3}$ by $\mathrm{Si}$ were observed during room temperature milling with the formation of $\alpha-\mathrm{Fe}$, amorphous $\mathrm{SiO}_{x}$, nanocrystalline $\mathrm{TiO}_{2}$, or intermetallic compounds, depending on the Si content. The mechanochemical reaction process consists of a mechanical activation stage and a reaction stage. Higher milling intensity leads to a shorter activation step and a higher reaction rate.

Order No.: JA812-025

(C) 1998 MRS

Predicting the spreading kinetics of high-temperature liquids on solid surfaces

D.A. Weirauch, Jr.

(Alcoa Technical Center)

The rate of movement of liquid drops towards their equilibrium position on smooth, horizontal, solid surfaces (spreading kinetics) is considered in this study. A model for nonreactive liquid spreading which was developed for low-temperature liquids is applied to results for a set of hightemperature liquids and room-temperature liquids. These data were generated in a single laboratory following a consistent experimental methodology. The liquid-solid pairs were chosen to result in weak or no interfacial chemical reaction. Furnace atmospheres were chosen to provide data for liquid metals with sub-monolayer, thin or thick oxide films. Analysis of the high-temperature spreading kinetics for liquids covering a broad range of viscosity, surface tension, and density shows that they can be predicted with a constant shift factor applied to the deGennes expression for nonreactive spreading. The consequences of gravitational and inertial forces, substrate roughness, weak interfacial reactions, and liquid-metal oxide films are discussed.

Order No.: JA812-026

(C) 1998 MAS

Crystal structure and dielectric property of epitaxially grown $(\mathrm{Ba}, \mathrm{Sr}) \mathrm{TiO}_{3}$ thin film prepared by metalorganic chemical vapor deposition H. Funakubo ${ }^{\star}$, Y. Takeshima ${ }^{+}$, D. Nagano*, K. Shinozaki*, N. Mizutani* ("Tokyo Institute of Technology, +Murata Mag. Co., Ltd.)

Epitaxially grown $(\mathrm{Ba}, \mathrm{Sr}) \mathrm{TiO}_{3}$ thin films were prepared on $(100) \mathrm{MgO}$ and $(100) \mathrm{Pt} / /(100) \mathrm{MgO}$ substrates by MOCVD. The lattice parameter increased with increasing $\mathrm{Ba} /(\mathrm{Ba}+\mathrm{Sr})$ ratio in the film and was higher than the reported value for bulk $(\mathrm{Ba}, \mathrm{Sr}) \mathrm{TiO}_{3}$.

The dielectric constant at room temperature reached to the maximum value at lower $\mathrm{Ba} /(\mathrm{Ba}+\mathrm{Sr})$ ratio compared to the reported one for bulk (Ba,Sr) $\mathrm{TiO}_{3}$. The temperature showing the maximum dielectric constant was higher than the reported value for bulk $(\mathrm{Ba}, \mathrm{Sr}) \mathrm{TiO}_{3}$. These results can be explained by the compressive stress applied to the film under the cooling process after the deposition.

Order No.: JA812-027

(C) 1998 MRS 
Prediction of nanoindentation hardness profile from a loaddisplacement curve

K.W. Xu* , G.L. Hou*, B.C. Hendrix*, J.W. He*, Y. Sun ${ }^{+}$, S. Zheng+,

A. Bloyce+, T. Bell+

("Xian Jiaotong University, +The University of Birmingham)

During the nanoindentation process, the load and depth data are continuously recorded. A single load-displacement curve is thus expected to contain material property information from the whole depth range indented. In the present paper, a new method to obtain the hardness-depth curve has been derived for small depths from the load-displacement curve measured at a large depth, based on the assumption that the elastic properties of the indented material can be obtained from the indentation depth. Using this method, hardness values can be computed for various small depths from a single load-displacement curve. From a series of nanoindentation experiments, it has been proven that the method can be used on both homogeneous and surface modified materials, such as fused silica, single crystal tungsten, and plasma nitrided steel with and without an iron nitride $\mathrm{Fe}_{4} \mathrm{~N}$ compound layer. Testings on series of $\mathrm{Ni}-\mathrm{P}$ films coated on $15 \mathrm{MnB}$ steel also gave fairly good results.

Order No.: JA812-028

(C) 1998 MRS

Theory of the charged cluster formation in the low pressure synthesis of diamond: Part I. Charge-induced nucleation

H.M. Jang ${ }^{\star}$, N.M. Hwang ${ }^{+}$

("Pohang University of Science and Technology, ${ }^{+}$Korea Research Institute of Standards and Science)

Based on several experimental observations, Hwang et al. recently proposed "the charged cluster model" [J. Cryst. Growth, 162, 55-68 (1996)] to disentangle the "puzzling thermodynamic paradox" encountered in the gas-activated chemical vapor deposition (CVD) of diamond. Many unusual phenomena observed in the CVD diamond process can be successfully approached by the charged cluster model. However, there are a couple of important subjects still unsolved quantitatively. The first question is connected with the main driving force for this unusual nucleation in the gas phase. The second issue is related to the difference in the thermodynamic stability between graphite and diamond for a nanometer-sized cluster during the growth. In this study, we have theoretically examined the thermodynamic driving forces for the charge-induced nucleation, in general, and have applied this idea to the nucleation of the charged carbon-atom cluster. It was shown that the short-range ion-induced dipole interaction and the ion-solvation electrostatic effect (Born term) were mainly responsible for this unusual nucleation in the gas phase. The theoretical analysis presented in this article is quite generic and, thus, can be applied to any process that involves the charge-induced nucleation.

Order No.: JA812-029

(C) 1998 MRS

Theory of the charged cluster formation in the low pressure synthesis of diamond: Part II. Free energy function and thermodynamic stability H.M. Jang ${ }^{*}$, N.M. Hwang ${ }^{+}$

('Pohang University of Science and Technology, ${ }^{+}$Korea Research Institute of Standards and Science)

To account for the dominant formation of diamond over graphite in the gas-activated CVD process we have theoretically examined the free energy function of a small carbon-atom cluster as a function of the cluster size. The scalar potential around a charged spherical cluster was derived using the linearized Poisson-Boltzmann equation. It was shown that the repulsive electrostatic energy associated with the growth of the charged diamond cluster was proportional to the fifth power of the cluster size. This suggests the existence of a deep potential-energy-well for the cluster size larger than the critical size corresponding to the free energy barrier for the nucleation. Thus, the growing diamond cluster will be trapped in this potential well before it transforms to the thermodynamically stable graphite. Considering all the relevant thermodynamic driving forces, we have constructed the free energy function in terms of the cluster size. The numerical computation also supports the existence of the potential-energywell. Therefore, the present theoretical model clearly explains why the charged diamond cluster does not transform to the neutral graphite cluster when the thermodynamic stability is reversed above a certain critical size during the growth.

Order No.: JA812-030

(c) $1998 \mathrm{MRS}$

Preparation and photoconductivity of poly[4-vinyl-pyridine]-CoPc seli-assembled film

M-M. Shi, M. Wang, H-Z. Chen

(Zhejiang University)

Through the complexation of cobalt phthalocyanine ( $\mathrm{CoPc}$ ) and a film of poly[4 vinyl-pyridine] (PVP) polarized by an electric field, a new type of preferentially oriented self-assembled film (PVP-CoPc) was obtained. The characterization of the film by DSC, angle-dependent XPS, and FTIR Reflection Absorption Spectroscopy (FTIR RAS) revealed that the planes of pyridine rings oriented perpendicular to the film surface, while the planes of phthalocyanine rings were oriented in parallel with, and coordinated on, the film surface. Photoconductivity study showed that the photoconductivities of the photoreceptors (P/Rs) made from the PVP-CoPc self-assembled film were much better than those from $\mathrm{CoPc}$ alone. These changes were ascribed to the charge transfer and the unique and ordered structure of PVP-CoPc self-assembled film.

Order No.: JA812-031

(c) 1998 MRS

\section{The adhesion energy between polymer thin films and seli-assembled} monolayers

A.V. Zhuk, A.G. Evans, J.W. Hutchinson, G.M. Whitesides (Harvard University)

A superlayer test has been adapted for the measurement of the fracture energy between epoxy thin films and self-assembled monolayers (SAMs) on Au/Ti/Si substrates. The "arrest" mode of analysis has been shown to provide consistent results, particularly when relatively wide lines are used to encourage lateral decohesions. The fracture energy, $\Gamma_{i}$, of the interface between the monolayer and the epoxy is varied by adjusting the ratio of $\mathrm{COOH} / \mathrm{CH}_{3}$ terminal groups. Connections between $\Gamma_{i}$, the surface energies, and the inelastic deformations occurring in the epoxy are explored upon comparison with interface crack growth simulations Order No.: JA812-032

(C) 1998 MRS

Quantitative nanoscale mechanical properties of a phase segregated homopolymer surface

J.F. Graham, M. Kovar, P.R. Norton, P. Pappalardo, J. Van Loon,

O.L. Warren

(University of Western Ontario)

Crystallization of poly(ethylene terephthalate) (PET) is accompanied by significant changes in surface topography, easily detected by atomic force microscopy (AFM). Phase imaging by AFM qualitatively indicates contrast in mechanical properties of nanometer scale areas of an annealed PET surface but cannot provide quantitative data. Using interfacial force microscopy (IFM), we have, for the first time, made quantitative measurements of the elastic moduli of such nm-scale areas on a homopolymer surface. Values of $2.2 \mathrm{GPa}, 4.3 \mathrm{GPa}$, and $11.8 \mathrm{GPa}$ were found, respectively, for amorphous PET and for phase segregated regions on the surface of an annealed homopolymer PET sample. The method is applicable to any phase segregated surface with $\mathrm{nm}$-sized domains of differing elastic moduli. Order No.: JA812-033

(C) 1998 MRS 
A transmission electron microscopy investigation of SiC films grown on Si(111) substrates by solid-source molecular beam epitaxy

U. Kaiser*, S.B. Newcomb+, W. M. Stobbs', M. Adamik* , A. Fissel*,

W. Richter ${ }^{*}$

("Friedrich-Schiller-Universitat Jena, + University of Cambridge, \#Research Institute for Technical Physics)

The effects of different growth parameters on the microstructure of the SiC films formed during simultaneous two-source molecular-beamepitaxial (MBE) deposition have been investigated. Substrate temperatures as low as $750-900^{\circ} \mathrm{C}$ have been used. The relationships between a number of different growth morphologies and deposition conditions have been established. The formation of single crystal $3 \mathrm{C}$ films has been found to occur at low growth rates but within a limited $\mathrm{Si}: \mathrm{C}$ adatom ratio. A combination of transmission electron microscopy (TEM) and atomic force microscopy (AFM) has been used to examine the different films, and the results of these investigations are described.

Order No.: JA812-034
Controlled partial melting during processing of dipcoated Bi-2212/Ag tapes.

A.L. Crossley, J.L. MacManus-Driscoll

(Imperial College of Science, Technology, and Medicine)

A detailed study has been made of the control and optimisation of partial melting of dipcoated $\mathrm{Bi}_{2} \mathrm{Sr}_{2} \mathrm{Ca}_{1} \mathrm{Cu}_{2} \mathrm{O}_{8+\delta} \mathrm{Ag}_{0.1}$ (Bi-2212) tapes using reduced oxygen partial pressures. A coulometric titration technique has been employed to vary the oxygen partial pressure in a region of the phase diagram corresponding to binary melting, and the amount of partial melting has been quantified. Using this information, tapes have been processed using both isothermal and isobaric techniques. An optimum processing route was determined which combined isothermal and isobaric processes. Highly aligned material at the point of optimum melting was obtained. Order No.: JA812-035

Please use the convenient postcard located in the back of the MRS Bulletin to order JMR reprints. When ordering single article reprints please note they are not available until the issue is published. See $J M R$ Abstracts on the MRS Website at http://www.mrs.org/publications//mr/jmra/.

\section{GET CONNECTED}

\section{BENEFITS OF MEMBERSHIP}

\section{Two Annual MRS Meetings}

As an MRS member, you'll automatically receive the Call for Papers and Program for upcoming meetings, as well as discounted MRS Meeting registration rates.

\section{MRS Bulletin}

The MRS Bulletin is your free monthly publication with timely news and features on the research and development of advanced materials.

\section{Journal of Materials Research}

Yours for a very low member rate, Journal of Materials Research is an international archival journal encompassing physical, chemical, and engineering research on advanced materials and processing techniques.

\section{MRS Books \& Videotapes}

As an MRS member, you may purchase MRS books and videotapes at 15-30\% below list price. You'll also enioy reduced rates for journals and books from other scientific publishers.

\section{Opportunities to Connect}

- Career services for members include the Job Center at MRS Spring and Fall Meetings.

- The annual Membership Directory is your connection to over 12,400 MRS members worldwide.

- Reduced membership renewal and meeting fees are available to unemployed or retired members, as well as recent graduates as yet unemployed.
The strength of MRS continues to be its members - and its ability to link its members-with connections in academia, industry, and government.

Get connected to the MRS interdisciplinary scientific community.

Submit your membership application today! $\mathrm{M}|\mathrm{R}| \mathrm{S}$

\section{FOR MORE INFORMATION}

Member Services

MATERIALS RESEARCH SOCIETY

506 Keystone Drive, Warrendale, PA 15086, USA

Telephone: $724-779-3003$

Facsimile: $724-779-8313$

E-mail: info@mrs.org

Web site: http://www.mrs.org/ 